\title{
Prevalence of Protective Shielding Utilization for Radiation Dose Reduction in Adult Patients Undergoing Body Scanning Using Computed Tomography
}

\author{
Shoaib Safiullah, MD, ${ }^{1,2}$ Roshan Patel, MD, ${ }^{1}$ Brittany Uribe, BS, ${ }^{1}$ Kyle Spradling, MD, \\ Chandana Lall, MD, Lishi Zhang, MS, Zhamshid Okhunov, MD, \\ Ralph V. Clayman, MD, and Jaime Landman, $\mathrm{MD}^{1,3}$
}

\begin{abstract}
Purpose: Ionizing radiation is implicated in nearly $2 \%$ of malignancies in the United States; radiation shields prevent unnecessary radiation exposure during medical imaging. Contemporary radiation shield utilization for adult patients in the United States is poorly defined. Therefore, we evaluated the prevalence of protective shielding utilization in adult patients undergoing CT scans in United States' hospitals.

Materials and Methods: An online survey was sent to established radiology departments randomly selected from the 2015 American Hospital Association Guide. Radiology departments conducting adult CT imaging were eligible; among 370 eligible departments, 215 departments accepted the study participation request. Questions focused on shielding practices during CT imaging of the eyes, thyroid, breasts, and gonads. Prevalence data were stratified per hospital location, size, and type. Main outcomes included overall protective shielding utilization, respondents' belief and knowledge regarding radiation safety, and organ-specific shielding prevalence.

Results: Sixty-seven of 215 (31\%) hospitals completed the survey; 66 (99\%) reported familiarity with the ALARA (as low as reasonably achievable) principle and $56(84 \%)$ affirmed their belief that shielding is beneficial. Only $60 \%$ of hospitals employed shielding during CT imaging; among these institutions, shielding varied based on CT study: abdominopelvic CT (13, 33\%), head CT $(33,83 \%)$, or chest CT (30, 75\%).

Conclusions: Among surveyed hospitals, $40 \%$ do not utilize CT shielding despite the majority acknowledging the ALARA principle and agreeing that shielding is a beneficial practice. Failure to address the low prevalence of protective shielding may lead to poor community health due to increased risk of radiation-related cancers.
\end{abstract}

Keywords: CT, radiation shielding, radiation dose reduction, imaging protocol

\section{Introduction}

$\mathbf{O}$ VER THE PAST THREE DECADES, the number of CT studies in the United States has risen more than 20 fold, reaching 70 million studies by $2007 .^{1-3}$ Given this rapid rise in CT utilization across the United States, it is becoming even more important for healthcare providers to be cognizant of the small, but substantial, health risks associated with ionizing radiation.

The typical radiation dose associated with a standard CT scan ranges from 1 to $14 \mathrm{mSv}$, equivalent to the total annual dose of natural radiation that an individual might receive. Radiation dose and its effect on biological tissues are concerning given that $1.5 \%$ to $2 \%$ of all cancers in the United States are estimated to be due to physician-initiated radiation exposure. $^{1,2}$ As a result of concerns over radiation exposure, The United States Nuclear Regulatory Commission developed regulations for radiation safety and established the commonly used acronym, ALARA ("as low as reasonably achievable") to stress the importance of minimizing radiation exposure. ${ }^{4}$ As such, many radiation dose-reduction protocols and CT shielding techniques have been developed.

The use of radiation shields is one of the simplest mechanisms by which radiation dose can be diminished without negatively impacting diagnostic image quality when applied appropriately. ${ }^{5-8}$ Within the past decade, several studies have shown the effectiveness of shielding in decreasing radiation dose exposure to the thyroid, ${ }^{9-12}$ breasts, ${ }^{11,13}$ eyes, ${ }^{7,9,10,14}$ and testes. ${ }^{12,14-17}$

\footnotetext{
${ }^{1}$ Department of Urology, University of California, Irvine, Orange, California.

${ }^{2}$ Division of Urology, University of Missouri, Columbia, Missouri.

${ }^{3}$ Department of Radiology, University of California, Irvine, Orange, California.

${ }^{4}$ Institute for Clinical and Translational Science, University of California, Irvine, Irvine, California.
} 
Accordingly, our objective was to evaluate the prevalence of protective shield utilization in adult patients undergoing routine abdominopelvic, chest, or head CT scans in a randomly selected group of U.S. hospitals.

\section{Materials and Methods}

\section{Survey design}

We designed a survey consisting of a series of multiplechoice questions pertaining to hospital CT imaging practices, use of organ-specific dosage-reduction protocols, and protective shielding practices, for adult patients. The respondents were first asked whether their department performed adult CT imaging; a negative reply resulted in exclusion from the study. If the reply was affirmative, the full-length questionnaire was presented for completion (Appendix 1). The survey was administered and data were collected using REDCap (Harvard Catalyst, Boston, MA) electronic data capture tools hosted at the University of Southern California. ${ }^{18}$ REDCap (Research Electronic Data Capture) is a secure, web-based application designed to support data capture for research studies.

\section{Participant selection and survey administration}

Between June 2015 and June 2016, we randomly selected and sent a study participation request to every seventh hospital of the 6295 U.S. hospitals listed in the American Hospital Association (AHA) Guide. Established radiology departments conducting adult CT imaging were eligible for this study. Eligible departments were contacted by phone or email to request the direct contact information for $\mathrm{CT}$ personnel (including CT technologists, CT supervisors, radiology managers, and radiation safety officers) capable of completing the survey. These individuals were sent an email invitation to complete the full online-based survey through REDCap. In the initial email, departments were asked to complete the survey within 4 weeks of receipt. Further contact was made with nonresponsive departments 2 weeks following initial contact and again 1 week before the end of the 4-week survey period. No patient-specific information was acquired or recorded during this study.

\section{Hospital data}

Descriptive data, including Census Divisions (numbered 1-9), teaching status, community hospital status, bed size data (6-199 beds, $\geq 200$ beds), type of authority responsible for establishing hospital policies (government, nongovernment, investor-owned/for-profit), were obtained from the AHA Guide. Other information, including hospital name, address, and contact information, were also recorded; hospitals were substratified by region (East, Midwest, West, and South).

\section{Study outcomes and statistical analysis}

Standard summary statistics were provided for hospital characteristics as well as the overall prevalence and the $95 \%$ confidence interval (CI) for protective shielding utilization. Similarly, point estimates and 95\% CIs were calculated for the respondents' belief in shielding protection, their awareness of shielding use by other hospitals, and their familiarity with the ALARA safety principle. We compared the prevalence of protective shielding utilization across hospital characteristics, including academic status (teaching or nonteaching), hospital size ( $\leq 199$ beds or $\geq 200$ beds), geographical region (East, Midwest, South, West), and for for-profit, government, or nongovernment status. These comparisons were based on two-sided Chi-squared tests as well as two-sided Fisher's exact tests when the expected cell counts were less than 5. Similarly, we contrasted the prevalence of protective shielding utilization with the respondents' belief in shielding protection, their awareness of shielding use by other hospitals, and their familiarity with the ALARA safety principles. Finally, we determined the prevalence of organspecific (i.e., eyes, thyroid, breasts, testes, and uterus and ovaries) shielding with $95 \%$ CIs among the 40 hospitals which employed protective shielding.

\section{Results}

We identified 370 hospitals with an established radiology department, among whom $62(17 \%)$ refused participation, 93 (25\%) did not respond after initial contact, 215 (58\%) accepted the survey request, and 83 (39\%) submitted responses. Table 1 lists the characteristics of the 67 hospitals that completed the survey. Table 2 reports the prevalence of shielding use at these hospitals (A) and the knowledge and attitudes of respondents with regard to shielding (B), followed by a comparison of shielding prevalence by hospital characteristics and by respondents' attitudes outlined in Table 3. A post hoc analysis comparing the South to all other regions showed no significant difference in use of shielding $(p=0.1008$, after adjusting for multiple comparisons).

A breakdown of the prevalence of shielding use by the type of CT imaging and shielded organs is provided in Table 4 and depicted in Figure 1. Of note, only $20 \%$ of these hospitals reported shielding during all three types of CT studies.

\section{Discussion}

The use of CT scans has dramatically increased, from about 3 million CT scans in 1980 to 70 million per year in 2007. ${ }^{1,3}$ The deleterious effects resulting from exposure to ionizing radiation can be divided into two types: deterministic and stochastic. Deterministic effects (e.g., epilation, cataracts, etc.) only occur after a certain threshold of radiation is exceeded

Table 1. Descriptive Summary of Hospital Characteristics

\begin{tabular}{llrc}
\hline Hospital characteristics & \multicolumn{1}{c}{ Category } & Count & Percent \\
\hline Teaching & No & 58 & 86.6 \\
& Yes & 9 & 13.4 \\
Bed size & $\geq 200$ beds & 23 & 34.3 \\
& $\leq 199$ beds & 44 & 65.7 \\
Region & East & 9 & 13.4 \\
& Midwest & 21 & 31.3 \\
& South & 18 & 26.9 \\
\multirow{3}{*}{ Government } & West & 19 & 28.4 \\
& Government & 11 & 16.4 \\
& For-profit & 12 & 17.9 \\
& Nongovernment & 44 & 65.7 \\
\hline
\end{tabular}


Table 2. (A) Overall Prevalence of Protective Shielding Utilization Among All 67 Hospitals and (B) Prevalence of Respondents' Belief and Knowledge About Shielding Protocols

\begin{tabular}{|c|c|c|c|c|}
\hline & $\mathrm{N}$ & Count & Percent & $95 \% C I$ \\
\hline \multicolumn{5}{|l|}{ (A) Utilization } \\
\hline Protective shielding utilization & 67 & 40 & 59.7 & $48.0,71.5$ \\
\hline \multicolumn{5}{|l|}{ (B) Belief and knowledge } \\
\hline Believe shielding is beneficial & 67 & 56 & 83.6 & $74.7,92.5$ \\
\hline Aware of shielding practices at other institutions & 67 & 25 & 37.3 & $25.7,48.9$ \\
\hline Familiar with ALARA safety principle & 67 & 66 & 98.5 & $95.6,100.0$ \\
\hline
\end{tabular}

$\mathrm{ALARA}=$ as low as reasonably achievable; $\mathrm{CI}=$ confidence interval.

and generally do not apply for the amount of radiation from CT scans. ${ }^{19}$ Stochastic effects, however, increase the probability of deleterious effects (e.g., genetic mutations and cancer) occurring with each radiation exposure, and therefore are an important concern with regard to CT imaging. ${ }^{20}$ Several studies have directly linked iatrogenic radiation exposure to cancer risk; indeed, a recent study by Leuraud and colleagues. demonstrated a strong positive association between cumulative lowdose radiation exposure and risk of death due to leukemia. ${ }^{2,21-25}$ Furthermore, the risk of developing solid cancers due to radiation exposure increases throughout adulthood until age $60 .{ }^{26}$ In this regard, there has been much interest in dose reduction to the imaged organs. For example, tube current modulation during abdominopelvic CT has dropped radiation exposure by as much as $68 \% .^{27,28}$

Using shields during CT scans is perhaps the simplest modality for decreasing patient radiation exposure. ${ }^{29} \mathrm{Nu}-$ merous studies have reported remarkable radiation dose reduction due to radiation shields. Indeed, a study by Hohl and colleagues regarding testicular shielding during abdominopelvic CT scans demonstrated a drop from a mean testicular radiation dose of 2.40 to $0.32 \mathrm{mSv}$, an $87 \%$ reduction in radiation dose to the testes without any diagnostic impairment. ${ }^{15}$ They additionally pointed out two other studies that showed similar dose reductions of $95 \%$ and $77 \%$ to the testicles. Another recent study investigating the effects of bismuth for eye shielding during brain CT scans demonstrated a $21 \%$ to $29 \%$ dose reduction to the lens of the eye, with no negative effect on CT image quality. ${ }^{7}$ Identically, Hopper and colleagues reported radiation dosage reduction of up to $50 \%$ when bismuth-coated latex shielding of the eye is used during cranial $\mathrm{CT}^{30}$ A similar study concerning breast and thyroid shielding during chest CT scans recorded a $30 \%$ and $50 \%$ dose reduction, respectively. ${ }^{31}$ Other studies have similarly corroborated significant dose reduction due to shielding techniques. ${ }^{9,11}$

Despite these striking numbers, radiation shielding has been a topic of debate in the literature. ${ }^{32}$ Some studies have indicated an increase in image noise in the area directly underlying the protective shield ${ }^{31,33,34}$; in contrast, other studies indicate no significant effect on diagnostic image quality. ${ }^{7,8,35}$ Radiation shields can be placed either over the area being studied and thus in the path of the radiation beam (i.e., "in-plane" shielding), or placed over areas outside of the

Table 3. Comparison of Shielding Utilization Prevalence by Hospital Characteristics and Respondents’ Knowledge About Protective Shielding

\begin{tabular}{|c|c|c|c|c|c|c|}
\hline & Category & $\mathrm{N}$ & Count & Percent & $95 \% C I$ & $\mathrm{p}$ \\
\hline \multicolumn{7}{|l|}{ Hospital characteristics } \\
\hline Teaching & $\begin{array}{l}\text { No } \\
\text { Yes }\end{array}$ & $\begin{array}{r}58 \\
9\end{array}$ & $\begin{array}{r}36 \\
4\end{array}$ & $\begin{array}{l}62.1 \\
44.4\end{array}$ & $\begin{array}{l}49.6,74.6 \\
11.9,76.9\end{array}$ & $0.4673^{\mathrm{a}}$ \\
\hline Bed size & $\begin{array}{l}\geq 200 \text { beds } \\
\leq 199 \text { beds }\end{array}$ & $\begin{array}{l}23 \\
44\end{array}$ & $\begin{array}{l}14 \\
26\end{array}$ & $\begin{array}{l}60.9 \\
59.1\end{array}$ & $\begin{array}{l}41.0,80.8 \\
44.6,73.6\end{array}$ & 0.8879 \\
\hline Region & $\begin{array}{l}\text { Eastern } \\
\text { Midwestern } \\
\text { Southern } \\
\text { Western }\end{array}$ & $\begin{array}{r}9 \\
21 \\
18 \\
19\end{array}$ & $\begin{array}{r}5 \\
11 \\
15 \\
9\end{array}$ & $\begin{array}{l}55.6 \\
52.4 \\
83.3 \\
47.4\end{array}$ & $\begin{array}{l}23.1,88.1 \\
31.0,73.8 \\
66.1,100.0 \\
24.9,69.9\end{array}$ & 0.1160 \\
\hline Government & $\begin{array}{l}\text { Government } \\
\text { For-profit } \\
\text { Nongovernment }\end{array}$ & $\begin{array}{l}11 \\
12 \\
44\end{array}$ & $\begin{array}{r}7 \\
9 \\
24\end{array}$ & $\begin{array}{l}63.6 \\
75.0 \\
54.6\end{array}$ & $\begin{array}{l}35.2,92.0 \\
50.5,99.5 \\
39.8,69.3\end{array}$ & 0.4372 \\
\hline $\begin{array}{l}\text { Knowledge about protective shielding } \\
\text { Believe shielding is beneficial }\end{array}$ & $\begin{array}{l}\text { No } \\
\text { Yes }\end{array}$ & $\begin{array}{l}11 \\
56\end{array}$ & $\begin{array}{r}1 \\
39\end{array}$ & $\begin{array}{r}9.1 \\
69.6\end{array}$ & $\begin{array}{r}0.0,26.1 \\
57.6,81.6\end{array}$ & $0.0003^{\mathrm{a}}$ \\
\hline Aware of shielding practices at other institutions & $\begin{array}{l}\text { No } \\
\text { Yes }\end{array}$ & $\begin{array}{l}42 \\
25\end{array}$ & $\begin{array}{l}23 \\
17\end{array}$ & $\begin{array}{l}54.8 \\
68.0\end{array}$ & $\begin{array}{l}39.7,69.9 \\
49.7,86.3\end{array}$ & 0.2853 \\
\hline Familiar with ALARA principle & $\begin{array}{l}\text { No } \\
\text { Yes }\end{array}$ & $\begin{array}{r}1 \\
66\end{array}$ & $\begin{array}{r}1 \\
39\end{array}$ & $\begin{array}{r}100.0 \\
59.1\end{array}$ & $\begin{array}{c}100.0,100.0 \\
47.2,71.0\end{array}$ & $1.0000^{\mathrm{a}}$ \\
\hline
\end{tabular}

${ }^{\mathrm{a}}$ Fisher's exact test two-sided $p$-value. 
Table 4. Organ-Specific Shielding Utilization Among the 40 Hospitals Which Used Protective Shielding

\begin{tabular}{|c|c|c|c|c|}
\hline CT type (organ shielded) & $\mathrm{N}$ & Count & Percent & $95 \% C I$ \\
\hline Head CT shielding & 40 & 33 & 82.5 & $70.7,94.3$ \\
\hline Chest CT shielding & 40 & 30 & 75.0 & $61.6,88.4$ \\
\hline Abdominopelvic CT shielding & 40 & 13 & 32.5 & $18.0,47.0$ \\
\hline Head CT (eyes) & 33 & 3 & 9.1 & $0.0,18.9$ \\
\hline Head CT (thyroid) & 33 & 7 & 21.2 & $7.3,35.1$ \\
\hline Head CT (breasts) & 33 & 24 & 72.7 & $57.5,87.9$ \\
\hline Head CT (testes) & 33 & 27 & 81.8 & $68.6,95.0$ \\
\hline Head CT (uterus and ovaries) & 33 & 29 & 87.9 & $76.8,99.0$ \\
\hline Chest CT (eyes) & 30 & 0 & 0.0 & - \\
\hline Chest CT (thyroid) & 30 & 1 & 3.3 & $0.0,9.7$ \\
\hline Chest CT (breast) & 30 & 9 & 30.0 & $13.6,46.4$ \\
\hline Chest CT (testes) & 30 & 22 & 73.3 & $57.5,89.1$ \\
\hline Chest CT (uterus and ovaries) & 30 & 22 & 73.3 & $57.5,89.1$ \\
\hline Abdominopelvic CT (eyes) & 13 & 1 & 7.7 & $0.0,22.2$ \\
\hline Abdominopelvic CT (thyroid) & 13 & 5 & 38.5 & $12.0,65.0$ \\
\hline Abdominopelvic CT (breasts) & 13 & 11 & 84.6 & $65.0,104.2$ \\
\hline Abdominopelvic CT (testes) & 13 & 0 & 0.0 & - \\
\hline Abdominopelvic CT (uterus and ovaries) & 13 & 0 & 0.0 & - \\
\hline
\end{tabular}

area of interest (i.e., "out-of-plane", shielding). This is an important distinction as "in-plane" shielding can increase image noise, and thereby reduce image quality. ${ }^{33}$ Additionally, if improperly applied, the dose reduction benefits of in-plane shielding can be lost. Following the results of their study investigating abdominal shielding during chest CT scans, Iball and Brettle strongly advocate for the use of "out-of-plane", shielding given the significant dose-reduction benefits and avoidance of potential image noise. ${ }^{8}$

In the foregoing national survey, we found that while the vast majority of radiology personnel responsible for conducting diagnostic adult CT imaging are aware of the ALARA safety principle, they believe that shielding practices are beneficial to patients. Despite this belief, overall only $60 \%$ of hospitals utilized radiation shields, and among these hospitals only $20 \%$ employ protective shielding for all three types of CT imaging. Similarly concerning is that while the ovaries cannot be shielded during abdominopelvic scanning, none of the hospitals elected to use gonadal shielding among their male patients during abdominopelvic CT scanning. With the increasing prevalence of CT imaging, there is significant opportunity to reduce ionizing radiation exposure with the thoughtful application of shielding.

In our post hoc analysis, we found notable variance with respect to organ-specific shielding practices. Gonadal shielding was more prevalent than shielding for the eyes or thyroid, and shielding during head and chest CT was more common than during abdominopelvic scans. One potential reason for this low use of shielding could be the effectiveness of dose reduction due to organ-based tube current modulation, in which CT tube current is automatically reduced when nearing certain organs. ${ }^{33,36,37}$ This type of automatic exposure control may counteract the shield. ${ }^{37}$ Therefore, several studies discourage concurrent shielding and tube current modulation. $5,29,37$

A limitation of our study was the low overall response rate; taking into account the 370 radiology departments we contacted, only $22 \%$ submitted a response, and $18 \%$ fully completed the survey. However, this concern is mitigated by the use of Fisher's exact test on the assessment of our data. Unfortunately, this does not account for the possibility that we may be over- or underestimating shielding compliance as we did not query nonhospital radiology service settings, such as surgical centers or clinics. Survey administration and response rate could have potentially been improved by sending a hardcopy letter first, followed by the actual web-based survey delivered through email. ${ }^{38,39}$ Another limitation of this study is that it was fully based on self-reporting from a single individual at each hospital; we did not audit responses nor confirm the compliance with shielding at the hospitals. Similarly, the reply was completed by a diverse array of individuals in the various radiology departments. This may indicate a possible reason for the low response rate, and may highlight a nonresponse bias in that individuals who did not complete the survey may have felt unqualified to respond. Another weakness of the study was that respondents were not queried regarding why they elected to not use shielding as we had, as it turned out, erroneously assumed that the use of shielding would be widespread. An additional consideration is that survey participants may have found the nature of this study to be provocative, and thus avoided responding. If so, we may have underestimated how many departments fail to shield patients.
FIG. 1. Prevalence of shielding (points) and 95\% confidence interval (horizontal lines).
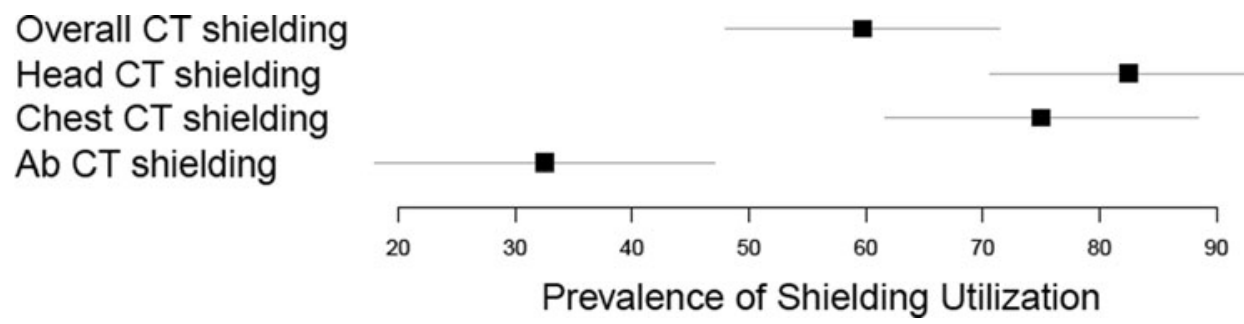


\section{Conclusions}

To the best of our knowledge, this is the first study to examine national shielding practices during CT imaging in adults. Given the steep rise in the use of CT scanning and recent information about the risk of radiation exposure associated with cancer, there is a need to limit radiation. In keeping with the ALARA principle, we believe that employing appropriate in-plane and out-of-plane shielding of all radiosensitive organs during CT imaging is a simple and necessary method to markedly reduce nontarget organ ionizing radiation exposure. Paradoxically, while the vast majority of radiology departments recognize the importance of ALARA and the benefit of shielding, most do not put these beliefs into practice. The reason for this conundrum has yet to be elucidated. Regardless, in our opinion, the next step is to better educate the public about the rise of radiation exposure in hope that patient demand for shielding will push more hospitals to adhere to their stated practices. In the hopefully near future, CT scanning without appropriate shielding may well be considered yet another "never event" which when violated would result in sanctions, both financial and reputational.

\section{Acknowledgments}

The authors thank Rahul Dutta, MD, for help with data collection, and Danh V. Nguyen, PhD and Tuyen Hoang, $\mathrm{PhD}$, for help with the data analysis. In addition, the authors acknowledge the statistical support received from the Institute for Clinical and Translational Science at the University of California, Irvine.

\section{Authors' Contributions}

All authors had a role in preparing this article.

\section{Author Disclosure Statement}

No competing financial interests exist.

\section{References}

1. Brenner DJ, Hall EJ. Computed tomography-An increasing source of radiation exposure. N Engl J Med 2007; 357:2277-2284.

2. Brenner DJ, Doll R, Goodhead DT, et al. Cancer risks attributable to low doses of ionizing radiation: Assessing what we really know. Proc Natl Acad Sci U S A 2003;100: 13761-13766.

3. Larson DB, Johnson LW, Schnell BM, Salisbury SR, Forman HP. National trends in CT use in the emergency department: 1995-2007. Radiology 2011;258:164-173.

4. NRC: 10 CFR Part 20.1003-Standards for protection against radiation. www.nrc.gov/reading-rm/doc-collections/ cfr/part020/full-text.html Accessed July 25, 2016.

5. Hohl C, Wildberger JE, Süß C, et al. Radiation dose reduction to breast and thyroid during MDCT: Effectiveness of an in-plane bismuth shield. Acta Radiol 2006;47:562-567.

6. Abou-Issa AH, Elganayni F, AL-Azzazy MZ. Effect of low tube $\mathrm{kV}$ on radiation dose and image quality in retrospective ECG-gated coronary CT angiography. Egypt J Radiol Nucl Med 2011;42:327-333.

7. Ciarmatori A, Nocetti L, Mistretta G, Zambelli G, Costi T. Reducing absorbed dose to eye lenses in head $\mathrm{Ct}$ examinations: The effect of bismuth shielding. Australas Phys Eng Sci Med 2016;39:583-589.
8. Iball GR, Brettle DS. Organ and effective dose reduction in adult Chest $\mathrm{Ct}$ using abdominal lead shielding. Br J Radiol 2011;84:1020-1026.

9. Ngaile JE, Uiso CBS, Msaki P, Kazema R. Use of lead shields for radiation protection of superficial organs in patients undergoing head CT examinations. Radiat Prot Dosimetry 2008; 130:490-498.

10. Liebmann M, Lüllau T, Kluge A, Poppe B, von Boetticher $\mathrm{H}$. Patient radiation protection covers for head CT scansA clinical evaluation of their effectiveness. RöFo 2014;186: 1022-1027.

11. Chung J-J, Cho E-S, Kang SM, Yu J-S, Kim DJ, Kim JH. Usefulness of a lead shielding device for reducing the radiation dose to tissues outside the primary beams during CT. Radiol Med (Torino) 2014;119:951-957.

12. Miri-Hakimabad H, Rafat-Motavalli L, Akhlaghi P. Effects of shielding the radiosensitive superficial organs of ORNL pediatric phantoms on dose reduction in computed tomography. J Med Phys 2014;39:238.

13. Foley SJ, McEntee MF, Rainford LA. An evaluation of inplane shields during thoracic CT. Radiat Prot Dosimetry 2013; 155:439-450.

14. Grobe H, Sommer M, Koch A, Hietschold V, Henniger J, Abolmaali N. Dose reduction in computed tomography: The effect of eye and testicle shielding on radiation dose measured in patients with beryllium oxide-based optically stimulated luminescence dosimetry. Eur Radiol 2008;19: 1156-1160.

15. Hohl C, Mahnken AH, Klotz E, et al. Radiation dose reduction to the male gonads during MDCT: The effectiveness of a lead shield. Am J Roentgenol 2005;184:128-130.

16. Fricker K, Thompson C, Meyer J. Assessment of concomitant testicular dose with radiochromic film. Australas Phys Eng Sci Med 2013;36:269-277.

17. Dauer LT, Casciotta KA, Erdi YE, Rothenberg LN. Radiation dose reduction at a price: The effectiveness of a male gonadal shield during helical CT scans. BMC Med Imaging 2007; 7:5.

18. Harris PA, Taylor R, Thielke R, Payne J, Gonzalez N, Conde JG. Research electronic data capture (REDCap) - A metadata-driven methodology and workflow process for providing translational research informatics support. J Biomed Inform 2009;42:377-381.

19. Frush DP, Applegate K. Computed tomography and radiation: Understanding the issues. J Am Coll Radiol 2004;1: 113-119.

20. Preston RJ. Update on linear non-threshold dose-response model and implications for diagnostic radiology procedures: Health Phys 2008;95:541-546.

21. Hall EJ, Brenner DJ. Cancer risks from diagnostic radiology. Br J Radiol 2008;81:362-378.

22. Mathews JD, Forsythe AV, Brady Z, et al. Cancer risk in 680000 people exposed to computed tomography scans in childhood or adolescence: Data linkage study of 11 million Australians. BMJ 2013;346:f2360.

23. McHugh K. CT scanning in children and risk of cancer: What three large-scale studies have demonstrated. Radiat Prot Dosimetry 2015;165:10-12.

24. Pearce MS, Salotti JA, Little MP, et al. Radiation exposure from CT scans in childhood and subsequent risk of leukaemia and brain tumours: A retrospective cohort study. Lancet 2012;380:499-505.

25. Leuraud K, Richardson DB, Cardis E, et al. Ionising radiation and risk of death from leukaemia and lymphoma in 
radiation-monitored workers (INWORKS): An international cohort study. Lancet Haematol 2015;2:e276-e281.

26. Shuryak I, Sachs RK, Brenner DJ. Cancer risks after radiation exposure in middle age. J Natl Cancer Inst 2010;102: $1628-1636$.

27. Huda W, Ogden KM, Khorasani MR. Converting doselength product to effective dose at CT. Radiology 2008; 248:995-1003.

28. Sabarudin A, Mustafa Z, Nassir KM, Hamid HA, Sun Z. Radiation dose reduction in thoracic and abdomen-pelvic CT using tube current modulation: A phantom study. J Appl Clin Med Phys 2015;16:319-328.

29. Lee YH, Park E, Cho PK, et al. Comparative analysis of radiation dose and image quality between thyroid shielding and unshielding during CT examination of the neck. Am J Roentgenol 2011;196:611-615.

30. Hopper KD, Neuman JD, King SH, Kunselman AR. Radioprotection to the eye during CT scanning. Am J Neuroradiol 2001;22:1194-1198.

31. Alonso TC, Mourão AP, Santana PC, da Silva TA. Assessment of breast absorbed doses during thoracic computed tomography scan to evaluate the effectiveness of bismuth shielding. Appl Radiat Isot 2016. doi:10.1016/j.apradiso .2016.03.018.

32. McCollough CH, Wang J, Gould RG, Orton CG. Point/ counterpoint: The use of bismuth breast shields for CT should be discouraged. Med Phys 2012;39:2321-2324.

33. Kim YK, Sung YM, Choi JH, Kim EY, Kim HS. Reduced radiation exposure of the female breast during low-dose chest CT using organ-based tube current modulation and a bismuth shield: Comparison of image quality and radiation dose. Am J Roentgenol 2013;200:537-544.

34. Einstein AJ, Elliston CD, Groves DW, et al. Effect of bismuth breast shielding on radiation dose and image quality in coronary CT angiography. J Nucl Cardiol 2012;19:100-108.

\section{Appendix 1. Radiology Imaging Shielding Questionnaire}

\section{CT Shielding Survey}

Please complete the survey below.

Hospital Name:

Date:

Full name of survey respondent:

Title of survey respondent:

1. Does your facility perform computed tomography (CT) scans on adults? Yes, No

2. When performing CT imaging, are protective shields used on the patients? Yes, No

3. For which CT protocols are protective shields used on patients? (Check all that apply):

Head, Chest, Abdominopelvic
35. Goren A, Prins R, Dauer L, et al. Effect of leaded glasses and thyroid shielding on cone beam CT radiation dose in an adult female phantom. Dentomaxillofacial Radiol 2013;42: 20120260.

36. Hoang JK, Yoshizumi TT, Choudhury KR, et al. Organ-based dose current modulation and thyroid shields: Techniques of radiation dose reduction for neck CT. Am J Roentgenol 2012;198:1132-1138.

37. Kubo T, Ohno Y, Kauczor HU, Hatabu H. Radiation dose reduction in chest CT-Review of available options. Eur J Radiol 2014;83:1953-1961.

38. Baruch Y, Holtom BC. Survey response rate levels and trends in organizational research. Hum Relat 2008;61: 1139-1160.

39. Kaplowitz MD, Hadlock TD, Levine R. A comparison of web and mail survey response rates. Public Opin Q 2004; 68:94-101.

Address correspondence to: Jaime Landman, $M D$

Department of Urology University of California, Irvine 333 City Boulevard West, Suite 2100

Orange, CA 92868

E-mail: landmanj@uci.edu

$\begin{aligned} & \text { Abbreviations Used } \\ \mathrm{AHA}= & \text { American Hospital Association } \\ \mathrm{ALARA}= & \text { as low as reasonably achievable } \\ \mathrm{CI} & =\text { confidence interval } \\ \mathrm{CT} & =\text { computed tomography } \\ \mathrm{mSv} & =\text { millisievert }\end{aligned}$

4. When performing head CT imaging, what organs are protected using shields? (Check all that apply):

Eyes, Breasts, Thyroid, Testes, Uterus/Ovaries

5. When performing chest CT imaging, what organs are protected using shields? (Check all that apply):

Eyes, Breasts, Thyroid, Testes,

Uterus/Ovaries

6. When performing abdominopelvic $\mathrm{CT}$ imaging, what organs are protected using shields? (Check all that apply):

Eyes, Breasts, Thyroid, Testes, Uterus/Ovaries

7. Do you believe shielding protocols would be beneficial to patients? Yes, No

8. Are you aware of shielding practices being used at other institutions? Yes, No

9. Are you familiar with the ALARA principle? Yes, No 